\title{
Individual correlates of self-stigma in patients with anxiety disorders with and without comorbidities
}

\author{
This article was published in the following Dove Press journal: \\ Neuropsychiatric Disease and Treatment \\ 17 July 2015 \\ Number of times this article has been viewed
}

\section{Marie Ociskova ${ }^{1,2}$ \\ Jan Prasko' \\ Dana Kamaradova' \\ Ales Grambal' \\ Zuzana Sigmundova'}

'Department of Psychiatry, University Hospital in Olomouc, Faculty of Medicine and Dentistry, ${ }^{2}$ Department of Psychology, Faculty of Arts, Palacky University in Olomouc, Olomouc, Czech Republic
Correspondence: Marie Ociskova Department of Psychiatry, University Hospital Olomouc, I P Pavlova 6, 77520 Olomouc, Czech Republic Tel +420 588443513

Email marie.ociskova@upol.cz
Background: A number of psychiatric patients experience stigma connected to prejudices about mental disorders. It has been shown that stigma is most harmful when it is internalized. Most of the studies were performed on individuals either with psychoses or with mood disorders, and hence, there are almost no studies with other diagnostic categories. The goals of this research were to identify factors that are significantly related to self-stigma in patients with anxiety disorders and to suggest possible models of causality for these relationships.

Methods: A total of 109 patients with anxiety disorders and possible comorbid depressive or personality disorders, who were admitted to the psychotherapeutic department participated in this study. All patients completed several psychodiagnostic methods, ie, the Internalized Stigma of Mental Illness Scale, Temperament and Character Inventory-Revised Version, Adult Dispositional Hope Scale, Dissociative Experiences Scale, Beck Anxiety Inventory, Beck Depression Inventory-Second Edition, and Clinical Global Impression (also completed by the senior psychiatrist).

Results: The overall level of self-stigma was positively associated with a comorbid personality disorder, more severe symptomatology, more intense symptoms of anxiety and depression, and higher levels of dissociation and harm avoidance. Self-stigma was negatively related to hope, reward dependence, persistence, self-directedness, and cooperativeness. Multiple regression analysis showed that the most significant factors connected to self-stigma are harm avoidance, the intensity of depressive symptoms, and self-directedness. Two models of causality were proposed and validated. It seems that the tendency to dissociate in stress increases the probability of development of self-stigma, and this relationship is entirely mediated by avoidance of harm. Conversely, self-directedness lowers the probability of occurrence of self-stigma, and this effect is partly mediated by hope.

Conclusion: Patients with anxiety disorders accompanied with or without comorbid depressive or personality disorders may suffer from self-stigma. Individuals with greater sensitivity to rejection and other socially aversive stimuli are prone to the development of self-stigma. Other personality factors, such as hopeful thinking and self-acceptance serve as factors promoting resilience concerning self-stigma.

Keywords: self-stigma, hope, Temperament and Character Inventory-Revised Version, clinical factors, demographic factors, anxiety disorders

\section{Introduction}

Negative attitudes toward individuals with mental disorders are still present in our society. They are deeply rooted culturally and are perpetuated by folklore and mass media. ${ }^{1}$ Prejudices concerning mental health issues and persons who suffer from them are often related to the expected dangers associated with psychiatric patients. ${ }^{1}$ The fears that stem from these prejudices do not take into consideration that most individuals with mental disorders are not violent or aggressive. ${ }^{2}$ Still, prejudices and the emotions 
connected to them shape the thinking and behavior of a considerable part of general society. ${ }^{3}$ Prejudice-based behavior may lead to direct (discriminative behavior) and indirect (gossip, disregarding) rejection of psychiatric patients. ${ }^{4}$

This social phenomenon is known as stigmatization. It has been hypothesized that patients with certain severe mental disorders (such as psychoses, bipolar affective disorder, and depression) tend to be targets of stigma. ${ }^{5}$ However, Alonso et $\mathrm{al}^{6,7}$ showed that individuals with minor psychiatric disorders, such as anxiety, may also be stigmatized.

Ritsher and Phelan $^{8}$ found that stigma is most harmful when it is internalized. Internalized stigma or self-stigma is a term for a state in which an individual accepts and agrees with societal prejudices about a particular condition (eg, mental disorders) and applies them to oneself., ${ }^{910}$ Self-stigma develops through three steps. Initially, the individual with a psychiatric diagnosis perceives the societal prejudices that relate to people with mental disorders. In the second step, the individual agrees with them. In the final step, the patient applies the prejudices to their own case, and then suffers from negative consequences of the internalization. ${ }^{11}$ Such a person then loses his/her former self-concept (I as a student, worker, or parent) and develops a new one, which is predominantly based on prejudices about the stigmatized condition (I as a dangerous, unreliable, and unpredictable lunatic). ${ }^{7}$ Self-stigma may lead to worse quality of life, ${ }^{11}$ insufficient adherence to psychiatric and psychotherapeutic treatment, ${ }^{10,12-14}$ or increased suicidal ideations and attempts. $^{15}$

Nevertheless, only some psychiatric patients suffer from self-stigma. Others do not develop it, even if they experience stigmatizing behavior. Thus, it seems that some patients are more resilient than others in regard to development of self-stigma. ${ }^{16}$ To date, several of such characteristics were identified.

\section{Self-stigma and demographic factors}

Livingston and Boyd ${ }^{5}$ performed a meta-analysis of the current state of knowledge concerning self-stigma in psychiatric patients. Considering the demographic characteristics of psychiatric patients, these authors concluded that none plays a significant role as a factor increasing or decreasing the probability of occurrence of self-stigma. The current evidence suggests that there are no significant differences in the level of self-stigma in patients of different sex, ethnicity, education, occupation, or income. ${ }^{5,16}$ Also, other research failed to identify any significant relationship between various demographic factors and self-stigma. ${ }^{14}$ The only demographic factor that might be meaningfully connected to self-stigma is the age of the individual. While most articles included in the analysis reported by Livingston and Boyd ${ }^{5}$ indicated that there is no significant relationship between age and self-stigma, a small number of analyzed studies did find such a relationship. Approximately, $63.6 \%$ of these studies reported that younger patients may be more prone to experiencing self-stigma than their older counterparts. The rest of the studies (36.4\%) showed an inverse relationship, ie, that elderly patients suffered from self-stigma significantly more often than younger patients. However, these findings are not robust and, according to Livingston and Boyd, ${ }^{5}$ can be ignored. The results of the studies focused on self-stigma in patients with bipolar disorder, ${ }^{15}$ psychoses, ${ }^{14}$ or anxiety disorder ${ }^{13,16}$ indicate that age does not influence the level of self-stigma in any significant way. Thus, the results of the available studies suggest that demographic factors do not play a meaningful role in shaping self-stigma.

\section{Self-stigma and clinical factors}

While demographic factors may be irrelevant, several clinical factors play a more significant role. Self-stigma is usually higher in patients with more pronounced and severe symptoms of mental illness. ${ }^{5,17}$ Other clinical factors such as type and duration of mental illness, insight into the disease, and level of functioning seem to be insignificant. Number of psychiatric hospitalizations, type of treatment (ambulatory, stationary, or inpatient), and side effects of medication are also not significant with regard to self-stigma. . $^{57-19}$

\section{Self-stigma and personality factors}

Several personality factors are related to self-stigma. Self-stigma is connected to lower self-esteem. ${ }^{10,11}$ Changes in self-concept are also frequent. Patients with higher levels of self-stigma lose their former self-concept (I as a husband, father, and worker) and create a new one based on prejudices (I as a dangerous and unpredictable person). ${ }^{11}$ Feelings of helplessness and hopelessness are also common. ${ }^{9,20}$

Patients with higher levels of self-stigma tend to experience more intense symptoms of depression and anxiety. ${ }^{8,21}$ Another emotional state, experienced by patients with self-stigma, is anxiety. According to Corrigan et al ${ }^{22}$ this is mainly anticipatory anxiety based on a fear of being recognized as an individual with mental struggles and rejected by others because of it. Rüsch et $\mathrm{al}^{23}$ found that individuals who stigmatize themselves tend to experience social anxiety. This negative emotional state produces and is reinforced by 
avoidant behavior. Individuals who suffer from internalized stigma tend to isolate themselves from society. ${ }^{24}$

Margetić et $\mathrm{al}^{25}$ used Cloninger's theory of personality to identify traits that are connected to self-stigma and thus serve as factors affecting vulnerability or resilience in its development. These authors found that the most significant trait linked to self-stigma was harm avoidance. ${ }^{25}$ Harm avoidance is a temperamental trait that includes characteristics such as shyness, fatigability, anticipatory worry, and inability to tolerate uncertainty. It presents a heritable tendency for intense reactions to aversive stimuli and learning to avoid punishment. ${ }^{26}$ This temperamental trait may be a factor that increases the probability of development of selfstigma later in life..$^{25}$ The second most significant trait was self-directedness. ${ }^{25}$ This trait may serve as a protective factor against development of self-stigma. Individuals with higher levels of this trait are resourceful, responsible, and purposeful. They accept themselves with their strengths and faults. They may be described as mature. ${ }^{27}$ Such characteristics make a person relatively independent in terms of self-concept and thus less vulnerable toward loss of self-esteem or hope and a change of self-concept during hard times. ${ }^{25}$

Another psychological factor that could be significantly related to self-stigma is dissociation. ${ }^{28}$ Dissociation is a defense mechanism that is used to deal with unbearable emotional states. ${ }^{29}$ It helps to create distance from currently experienced or anticipated feelings of anxiety, fear, pain, or helplessness. ${ }^{30}$ The overwhelming parts of the psyche are dissociated and pushed outside of the reach of consciousness. ${ }^{31}$ Adults who largely rely on dissociation in times of stress have often experienced trauma or neglect. They were exposed to helplessness and were unable to deal with the perceived stress in more adaptive ways than offered dissociation. ${ }^{32}$ According to Irwin, ${ }^{33}$ early trauma is one of the reasons why individuals who excessively dissociate are prone to the feelings of shame and guilt. They also tend to dissociate when they perceive similar feelings in adulthood. ${ }^{34}$ This creates a vicious cycle. Individuals, who preferentially use dissociation as a coping mechanism are more prone to feelings of shame and guilt. They may be vulnerable to developing self-stigma as well because the primary emotional basis of self-stigma is the feeling of shame. ${ }^{6,35}$

The majority of studies reported to date have focused on self-stigma in patients with psychoses or affective mood disorders. ${ }^{8-10}$ Livingston and Boyd ${ }^{5}$ reported that more than half of the studies they analyzed focused on patients with psychoses $(54.3 \%)$ and another quarter $(26.5 \%)$ considered self-stigma in patients with a mood and/or anxiety disorder.
However, there was a lack of studies focusing specifically on patients with minor neurotic or anxiety disorders or addressing the relationship between self-stigma and dissociation. The research presented in this paper had two goals, ie, to identify demographic, clinical, and psychological factors that are significantly connected to self-stigma in adults with anxiety disorders and to suggest possible causal chains between significant personality traits and internalized stigma.

\section{Patients and methods}

A total of 109 patients admitted to a psychotherapeutic department at the University Hospital in Olomouc were enrolled in this study. The inclusion criteria were age $>18$ years and a diagnosis of anxiety disorder according to International Classification of Diseases Tenth Revision (ICD-10) ${ }^{36}$ criteria (ie, social phobia, panic disorder with/without agoraphobia, generalized anxiety disorder, mixed anxiety and depressive disorder, comorbid depressive disorder, or personality disorder was possible). The exclusion criteria were a diagnosis of organic mental disorder, psychosis, current substance use disorder, or dissocial personality disorder and significant suicidal tendency. Three independent psychiatrists performed the diagnostic tests, and the diagnoses were confirmed by a Mini-International Neuropsychiatric Interview (MINI) ${ }^{37}$ administered by a psychologist.

\section{Measurements}

All patients signed an informed consent form and completed several psychodiagnostic assessments. The following tests were administered at the start of hospitalization.

\section{Mini-International Neuropsychiatric Interview}

The MINI is a short diagnostic interview allowing diagnosis of several psychiatric disorders according to the Diagnostic and Statistical Manual of Mental Disorders, Fourth Edition (DSM-IV) and ICD-10, ie, major depression, dysthymia, hypomanic/manic episode, panic disorder, agoraphobia, social phobia, obsessive-compulsive disorder, generalized anxiety disorder, substance use disorders, psychoses, anorexia, bulimia, and suicidal risk. ${ }^{37}$ The interview takes approximately 15-20 minutes to complete, and its psychometric properties are satisfactory. ${ }^{38}$

\section{Internalized Stigma of Mental IIlness}

The Internalized Stigma of Mental Illness (ISMI) scale ${ }^{39}$ measures the level of self-stigma in adults with mental disorders. It consists of 29 statements divided into five subscales, ie, 
alienation, stereotype endorsement, discrimination experience, social withdrawal, and stigma resistance. Participants mark a number from 1 to 4 for each item, according to the level of agreement/disagreement with the statements. ${ }^{39}$ The overall scale scores possible range from 29 to 116 , with 63 and 64 being the average scores for self-stigma (ie, a T-score of 50). ${ }^{17}$ Internal consistency of the scale is excellent. ${ }^{39}$ The same holds true with the Cronbach's alpha for the Czech translation of the scale $(\alpha=0.91)$ which also has very good reliability when analyzed by the split-half method (Spearman-Brown coefficient 0.93) and on test-retest 3 weeks after the first measurement $(r=0.90, P<0.001) .{ }^{17}$

\section{Adult Dispositional Hope Scale}

The Adult Dispositional Hope Scale (ADHS) scale ${ }^{40}$ measures the level of hope according to the theory of hope created by Snyder. The method includes 12 items. Individuals choose a number from a Likert scale of $1-8$ according to the level of agreement with each statement. Four items measure pathway thinking (ie, ability to find realistic ways to achieve desired goals), four items measure agency (ie, motivation to pursue goals and remain focused on these goals in spite of frustration and failure), and the remaining four items serve as distractors and are not analyzed. The whole scale scores range from 8 to 64 , with higher scores indicating higher levels of hope. The overall rating of 48 is considered to be average for a nonclinical population. ${ }^{40,41}$ Internal consistency of the scale is good $(\alpha=0.74-0.84) .{ }^{40}$ Standardization of the Czech version of the scale is now in progress. Current data show good internal consistency of the translation $(\alpha=0.82) .{ }^{41}$

\section{Temperament and Character Inventory-Revised Version}

The Temperament and Character Inventory-Revised Version (TCI-R $)^{42,43}$ is based on the biosocial theory of personality created by Cloninger. It consists of 240 items that measure seven personality traits, including five validity items. The temperamental traits are novelty seeking (35 items, with a smallest possible score of 35 and a highest possible score of 175), harm avoidance (33 items, with a smallest possible score of 33 and a highest possible score of 165), reward dependence (30 items, with a smallest possible score of 30 and a highest possible score of 150), and persistence (35 items, with a smallest possible score of 35 and a highest possible score of 175). The character traits are self-directedness (40 items, with a smallest possible score of 40 and a highest possible score of 200), cooperativeness (36 items, with a smallest possible score of 36 and a highest possible score of 180), and self-transcendence (26 items, with a smallest possible score of 26 and a highest possible score of 130). ${ }^{43}$ Participants respond to the items using a 5-point Likert scale according to the level of agreement with each statement. Internal consistency of the inventory seems satisfactory, ${ }^{44}$ and the reliability of the Czech version of the method is good. ${ }^{45}$

\section{Clinical Global Impression}

The Clinical Global Impression (CGI ${ }^{46}$ is a scale that evaluates the overall level of psychopathology. It is based on a scale of 1-7, where every point has a different description. A score of 1 indicates no presence of symptoms of a mental disorder. A medium score of 4 indicates that the individual is moderately mentally ill, and a score of 7 indicates extremely severe symptoms of mental illness. ${ }^{46}$ The scale may be completed by a physician (objCGI), or a patient (subjCGI). ${ }^{46}$ The internal consistency of the scale is satisfactory. ${ }^{47}$

\section{Beck Anxiety Inventory}

The Beck Anxiety Inventory (BAI) ${ }^{48}$ includes 21 symptoms of anxiety. Probands choose the signs they have perceived in the last week and how intensive or unpleasant they were. ${ }^{48}$ The smallest possible score is 0 and the highest score is 63 . A score up to 9 points indicates normal levels of anxiety, a score ranging from 10 to 18 indicates a mild to moderate intensity of anxiety, a score from 19 to 29 indicates moderate to severe anxiety, and scores higher than 30 indicate severe anxiety. ${ }^{48}$ The scale has excellent internal consistency. ${ }^{49,50}$ Validation of the Czech version of this scale is currently in progress. The Cronbach's alpha for the translation is excellent $(\alpha=0.92) .{ }^{51}$

\section{Beck Depression Inventory-Second Edition}

The Beck Depression Inventory-Second Edition (BDI-II) ${ }^{52}$ consists of 21 symptoms of depression. Participants choose how intense their symptoms were in the last 2 weeks. ${ }^{52}$ The smallest possible score is 0 and the highest obtainable score is 63 points. Scores up to 9 points indicate normal levels of depressive symptoms and scores between 10 and 15 points indicate minimal symptoms of depression. Scores ranging between 16 and 19 indicate mild to moderate depressive symptoms, and scores from 20 to 29 points indicate moderate to severe depression. Scores higher than 30 indicate severe depressive symptoms. ${ }^{53}$ Internal consistency of the scale is good. The reliability is higher in the psychiatric population $(\alpha=0.86)$ than in the general population $(\alpha=0.81) .{ }^{53}$ The Czech version of the scale has been standardized and published by Preiss and Vacir. ${ }^{54}$ 


\section{Dissociative Experiences Scale}

The Dissociative Experiences Scale (DES) ${ }^{55}$ consists of 28 types of dissociative experiences. Individuals mark a spot on a $10 \mathrm{~cm}$ line according to the percentage of time in which they experience the symptoms. The overall score shows the intensity of the dissociative experiences. It is also possible to calculate a score of pathological dissociation (DES-T) that includes items $3,5,7,8,12,13,22$, and 27 . These items focus on pathological experiences of derealization, depersonalization, identity alteration, and dissociative amnesia. ${ }^{56}$ Some authors suggest a cut-off score of 45-55 points to identify individuals with dissociative disorders. ${ }^{57}$ The internal consistency of the scale is excellent $(\alpha=0.96) .{ }^{55}$ The Czech version of the scale has similar psychometric properties. ${ }^{58}$

\section{Statistical analysis}

The statistical analysis was performed using Statistical Package for the Social Sciences version 17.0 and GraphPad Prism version 5.0. Descriptive statistics was applied to the demographic data, calculations of the average scores and data distribution. Differences between groups were determined by unpaired $t$-tests and one-way analysis of variance. Relationships between factors were analyzed by Pearson or Spearman correlation and multiple regressions, ie, a backward stepwise regression analysis. Hypotheses about causal relationships were tested by using path analysis. The significance of the mediators was evaluated by the Sobel test. The threshold for statistical significance was set at 5\%.

The research was conducted according to the latest version of the Declaration of Helsinki and the Guideline for Good Clinical Practice. ${ }^{59}$ The study was approved by the local ethics committee.

\section{Results Subjects}

A total of 184 patients admitted to the psychotherapeutic department of the University Hospital in Olomouc were invited to participate in this study, of whom 145 agreed to take part. Thirty-six patients were excluded, mainly due to a change in the primary diagnosis. The final group of participants included 109 patients. The mean age of the group was $40.0 \pm 12.1$ years. The youngest participant was 18 years old and the eldest was aged 70 . The average age at onset of illness was $31.1 \pm 14.3$ years. The primary diagnosis was anxiety disorder in all cases. The average duration of the illness was $8.5 \pm 8.1$ years. The participants had had an average of $2.1 \pm 1.5$ psychiatric hospitalizations. Fifty-one patients were being hospitalized in a psychiatric department for the first time in their life. One individual had had ten psychiatric hospitalizations. Other demographic and clinical characteristics are presented in Tables 1 and 2.

Most of the patients were women $(n=73 ; 66.9 \%)$, and the majority were students or employed $(n=62 ; 56.9 \%)$. The remainder were unemployed $(n=25 ; 22.9 \%)$ and/or were receiving a disability benefit or the old age pension $(n=22$; $20.2 \%$ ). The most common level of education was secondary school ( $\mathrm{n}=51 ; 46.8 \%)$, followed by lower vocational training $(n=30 ; 27.5 \%)$ and both primary school $(n=14 ; 12.8 \%)$ and university $(\mathrm{n}=14 ; 12.8 \%)$. Most of the study participants were single $(n=40 ; 36.7 \%)$ or married $(n=39 ; 35.8 \%)$. Twentythree patients $(21.1 \%)$ were divorced and another seven individuals (6.4\%) were widowed.

The primary diagnosis in all patients was anxiety disorder. Eleven patients (10.1\%) suffered from agoraphobia and 28 (25.7\%) were diagnosed with panic disorder. Others suffered from social phobia $(n=26 ; 23.9 \%)$ or generalized anxiety disorder $(\mathrm{n}=36 ; 33.0 \%)$. Mixed anxiety-depressive disorder was the least common diagnosis $(\mathrm{n}=8 ; 7.3 \%)$. Comorbid disorders were present in 96 patients (88.1\%), with 32 (29.4\%) being diagnosed with comorbid depression, 31 (28.4\%) with comorbid personality disorder (mainly borderline personality disorder; $\mathrm{n}=21 ; 19.3 \%)$. Twenty-five patients $(22.9 \%)$ were diagnosed with comorbid anxiety disorder.

\section{Medication}

Antidepressants were the most common medication used by the participants $(97 ; 89.0 \%)$. The mean dose of the medication was $47.50 \pm 31.24 \mathrm{mg}$ of paroxetine equivalent. Some

Table I Demographic data of the participants

\begin{tabular}{ll}
\hline Demographic categories & Patients, $\mathbf{n}(\%)$ \\
\hline All patients & $109(100)$ \\
Sex & \\
Women & $73(66.9)$ \\
Men & $36(33.1)$ \\
Occupation & \\
Student and employees & $62(56.9)$ \\
Unemployed & $25(22.9)$ \\
Disability rent (old age pension) & $22(20.2)$ \\
Education & \\
Primary school & $14(12.8)$ \\
Lower vocational training & $30(27.5)$ \\
Secondary school & $51(46.9)$ \\
University & $14(12.8)$ \\
Marital status & \\
Single & $40(36.7)$ \\
Married & $39(35.8)$ \\
Divorced & $23(21.1)$ \\
Widowed & $7(6.4)$ \\
\hline
\end{tabular}


Table 2 Primary diagnoses, comorbidities, and medication

\begin{tabular}{|c|c|c|c|c|c|c|}
\hline \multirow{2}{*}{$\begin{array}{l}\text { Numbers of patients/mg } \\
\text { of medication }\end{array}$} & \multicolumn{6}{|c|}{ Anxiety disorders } \\
\hline & $\begin{array}{l}\text { All anxiety } \\
\text { disorders }\end{array}$ & Agoraphobia & $\begin{array}{l}\text { Panic } \\
\text { disorder }\end{array}$ & $\begin{array}{l}\text { Social } \\
\text { phobia }\end{array}$ & $\begin{array}{l}\text { Generalized } \\
\text { anxiety } \\
\text { disorder }\end{array}$ & $\begin{array}{l}\text { Mixed anxiety- } \\
\text { depressive } \\
\text { disorder }\end{array}$ \\
\hline$n(\%)$ & $109(100)$ & II (I0.I) & $28(25.7)$ & $26(23.9)$ & $36(33.0)$ & $8(7.3)$ \\
\hline Mean objective CGI score & $4.30 \pm I .1$ & $4.2 \pm 0.9$ & $4.6 \pm 1.0$ & $4.0 \pm 1.0$ & $4.4 \pm 1.2$ & $4.8 \pm 1.3$ \\
\hline Mean BAI score & $25.10 \pm 12.3$ & $26.5 \pm 13.1$ & $28.7 \pm 13.0$ & $20.8 \pm 10.9$ & $24.8 \pm 12.1$ & $26.4 \pm 13.4$ \\
\hline \multicolumn{7}{|l|}{ Comorbidities } \\
\hline Without & 13 & 2 & 0 & 4 & 4 & 3 \\
\hline One disorder & 42 & 3 & 12 & 8 & 16 & 3 \\
\hline Two disorders & 32 & 5 & 7 & 10 & 9 & 1 \\
\hline Three and more disorders & 22 & I & 9 & 4 & 7 & 1 \\
\hline Personality disorder & 31 & 2 & 12 & 5 & 8 & 4 \\
\hline Depression & 32 & 3 & 9 & 8 & 12 & 0 \\
\hline Other anxiety disorder & 25 & I & 9 & 12 & 3 & 0 \\
\hline \multicolumn{7}{|l|}{ Medication (n) } \\
\hline Antidepressants & $47.50 \mathrm{mg}(97)$ & $38.18 \mathrm{mg}(\mathrm{II})$ & $56.20 \mathrm{mg}(27)$ & $39.50 \mathrm{mg}(20)$ & $40.78 \mathrm{mg}(32)$ & $62.86 \mathrm{mg}(7)$ \\
\hline Anxiolytics & $0.67 \mathrm{mg}(40)$ & $0.83 \mathrm{mg}(5)$ & $\mathrm{I} .07$ mg (II) & $0.33 \mathrm{mg}(3)$ & $0.81 \mathrm{mg}(17)$ & $0.31 \mathrm{mg}(4)$ \\
\hline Antipsychotics & $1.31 \mathrm{mg}(28)$ & $1.58 \mathrm{mg}(3)$ & $1.48 \mathrm{mg}(5)$ & $0.63 \mathrm{mg}(8)$ & 1.73 mg (8) & $1.11 \mathrm{mg}(4)$ \\
\hline \multicolumn{7}{|l|}{ Combinations } \\
\hline Two medications & 39 & 6 & 7 & 7 & 16 & 3 \\
\hline Three medications & 12 & I & 4 & 1 & 4 & 2 \\
\hline Without medication & 6 & 0 & 1 & 3 & 2 & 0 \\
\hline
\end{tabular}

Notes: Antidepressants, given as paroxetine equivalent; anxiolytics given as alprazolam equivalent; antipsychotics refers to second-generation agents given as risperidone equivalent.

Abbreviations: CGI, Clinical Global Impression; BAI, Beck Anxiety Inventory.

patients were being treated with anxiolytics $(40 ; 36.7 \%)$ at a dose representing $0.67 \pm 0.82 \mathrm{mg}$ of alprazolam equivalent. Twenty-eight patients $(25.7 \%)$ were taking antipsychotics at a mean dose representing $1.31 \pm 1.23 \mathrm{mg}$ of risperidone equivalent (Table 2).

\section{Mean scores on the scales}

The mean level of self-stigma was average when compared with the norms for the psychiatric population (Table 3). ${ }^{17}$ The mean level of hope was lower than the average score

Table 3 Scales, subscales, and mean scores

\begin{tabular}{llll}
\hline $\begin{array}{l}\text { Scalel } \\
\text { subscale }\end{array}$ & $\begin{array}{l}\text { Overall } \\
\text { mean score }\end{array}$ & $\begin{array}{l}\text { Scalel } \\
\text { subscale }\end{array}$ & $\begin{array}{l}\text { Mean } \\
\text { score }\end{array}$ \\
\hline ISMI & $65.10 \pm 11.5$ & NS & $96.4 \pm 14.4$ \\
Hope & $34.2 \pm 12.0$ & HA & $121.3 \pm 18.9$ \\
SubjCGI & $4.4 \pm 1.3$ & RD & $95.6 \pm 13.4$ \\
ObjCGI & $4.3 \pm 1.1$ & PS & $98.8 \pm 22.9$ \\
BAI & $25.1 \pm 12.3$ & SD & $123.0 \pm 20.0$ \\
BDI-II & $25.0 \pm 10.3$ & CO & $124.6 \pm 15.7$ \\
DES & $14.5 \pm 12.6$ & ST & $64.9 \pm 14.6$ \\
\hline
\end{tabular}

Note: Hope indicates the overall score on the Adult Dispositional Hope Scale. Abbreviations: NS, novelty seeking; HA, harm avoidance; RD, reward dependence; PS, persistence; SD, self-directedness; CO, cooperativeness; ST, self-transcendence; SubjCGI, Clinical Global Impression, subjective version; objCGI, Clinical Global Impression, objective version; BAI, Beck Anxiety Inventory; BDI-II, Beck Depression Inventory-Second Edition; DES, Dissociative Experiences Scale; ISMI, Internalized Stigma of Mental Illness. for the general population. ${ }^{40}$ Both the subjective and objective versions of the CGI indicated that the participants had moderately severe mental illness on average. ${ }^{46}$ Mean levels of anxiety (BAI) and depression (BDI-II) were moderate according to the cut-off scores. ${ }^{48,53}$ The average level of dissociation was in the nonpathological range..$^{57}$ Table 3 shows the mean scores for the subscales of the TCI-R inventory.

\section{Self-stigma and demographic factors}

The mean age at onset of anxiety disorder was $31.1 \pm 14.3$ years. The average duration of the disorder was $8.5 \pm 8.1$ years. The participants had had an average of $2.1 \pm 1.5$ psychiatric hospitalizations. Fifty-one patients were being hospitalized in a psychiatric department for first time in their life. One individual had had ten psychiatric hospitalizations. Taking into consideration the overall level of the ISMI scale, the results did not indicate any demographic factors as being significantly connected to self-stigma (Table 4). However, several demographic factors were significantly correlated with subscales of the ISMI. The sooner the anxiety disorder had developed, the more the patient felt alienated from their social environment and the more they perceived discrimination on the part of others (Table 4). Increasing duration of mental illness was connected to more endorsement of stereotypes about psychiatric patients (Table 4). Perceived 
Table 4 Self-stigma and demographic factors

\begin{tabular}{|c|c|}
\hline Demographic factors & Overall score of ISMI \\
\hline Age & $r=-0.11 ; N S^{p}$ \\
\hline Age of onset of disorder & $r=-0.16 ; N^{P}$ \\
\hline Duration of disorder & $r=0.15 ; \mathrm{NS}^{\mathrm{S}}$ \\
\hline Number of psychiatric hospitalizations & $r=0.16 ; N^{s}$ \\
\hline \multicolumn{2}{|l|}{ Sex } \\
\hline Female & $66.2 \pm 11.3$ \\
\hline Male & $62.9 \pm 11.9$ \\
\hline Unpaired t-test & $t=1.393 \mathrm{df}=107 ; \mathrm{NS}$ \\
\hline \multicolumn{2}{|l|}{ Education } \\
\hline Primary school & $71.3 \pm 10.6$ \\
\hline Lower vocational training & $63.8 \pm 12.0$ \\
\hline Secondary school & $63.8 \pm 12.3$ \\
\hline University & $66.6 \pm 6.2$ \\
\hline One-way ANOVA & $F=0.1948 ; d f=108 ; N S$ \\
\hline \multicolumn{2}{|l|}{ Marital status } \\
\hline Single & $65.8 \pm 11.0$ \\
\hline Married & $64.3 \pm 12.0$ \\
\hline Divorced & $66.5 \pm 13.0$ \\
\hline Widowed & $61.4 \pm 10.1$ \\
\hline One-way ANOVA & $F=0.7202 ; d f=108 ; N S$ \\
\hline \multicolumn{2}{|l|}{ Job } \\
\hline Employed and students & $64.7 \pm 11.8$ \\
\hline $\begin{array}{l}\text { Unemployed and/or taking } \\
\text { disability rent or old age pension }\end{array}$ & $65.7 \pm 11.3$ \\
\hline Unpaired $t$-test & $t=0.455 d f=107 ; N S$ \\
\hline
\end{tabular}

Notes: $P$, Pearson r; s, Spearman r.

Abbreviations: ANOVA, analysis of variance; ISMI, Internalized Stigma of Mental Illness; NS, not statistically significant.

discrimination also correlated positively with the number of previous psychiatric hospitalizations. The number of hospitalizations was also positively connected with withdrawal from society (Table 4). Most often, patients with only primary education perceived discriminatory behavior.

\section{Self-stigma and clinical factors}

The participants were divided into three groups according to the similarities and differences in their primary diagnosis. Thus, the first group consisted of 39 patients who suffered from panic disorder or agoraphobia because these two disorders are often comorbid, the second group consisted of 26 patients with social phobia, and the third group consisted of 44 individuals with generalized anxiety disorder or mixed anxiety-depressive disorder. This process allowed us to compare the tendency for development of self-stigma in participants with different primary diagnoses and to do so in groups containing a relatively similar number of subjects. The mean level of self-stigma was not significantly different between the three groups of participants (Table 5).
Table 5 Self-stigma and clinical factors

\begin{tabular}{|c|c|}
\hline Clinical factors & Overall ISMI score \\
\hline \multicolumn{2}{|l|}{ Major diagnosis } \\
\hline Panic disorder and agoraphobia & $66.7 \pm 10.7$ \\
\hline Social phobia & $65.2 \pm 10.5$ \\
\hline GAD and MADD & $63.6 \pm 12.3$ \\
\hline One-way ANOVA & $F=0.7452 ; d f=108 ; N S$ \\
\hline \multicolumn{2}{|l|}{ Comorbid depression } \\
\hline With depression & $65.9 \pm 10.9$ \\
\hline Without depression & $64.8 \pm 11.9$ \\
\hline Unpaired $t$-test & $t=0.4679 \mathrm{df}=107 ; \mathrm{NS}$ \\
\hline \multicolumn{2}{|l|}{ Comorbid anxiety disorder } \\
\hline With comorbid anxiety disorder & $65.7 \pm 11.2$ \\
\hline Without comorbid anxiety disorder & $64.2 \pm 12.2$ \\
\hline Unpaired $t$-test & $t=0.6673 \mathrm{df}=107 ; \mathrm{NS}$ \\
\hline \multicolumn{2}{|l|}{ Comorbid personality disorder } \\
\hline With PD & $69.2 \pm 9.1$ \\
\hline Without PD & $63.5 \pm 12.1$ \\
\hline Unpaired $t$-test & $t=2.384 d f=107 ; P<0.05$ \\
\hline \multicolumn{2}{|l|}{ Familial heredity } \\
\hline With heredity & $65.6 \pm 10.3$ \\
\hline Without heredity & $64.6 \pm 12.7$ \\
\hline Unpaired $t$-test & $t=0.4740 \mathrm{df}=107 ; \mathrm{NS}$ \\
\hline BAI & $r=0.33 ; P<0.00 I^{P}$ \\
\hline BDI-II & $r=0.55 ; P<0.00 I^{P}$ \\
\hline SubjCGI & $r=0.30 ; P<0.01^{\mathrm{s}}$ \\
\hline ObjCGI & $r=0.3 \mathrm{I} ; P<0.0 \mathrm{I}^{\mathrm{s}}$ \\
\hline
\end{tabular}

Notes: $P$, Pearson $r$; s, Spearman $r$.

Abbreviations: ANOVA, analysis of variance; GAD, generalized anxiety disorder; MADD, mixed anxiety-depressive disorder; PD, personality disorder; BAI, Beck Anxiety Inventory; BDI-II, Beck Depression Inventory, Second Edition; subjCGI, Clinical Global Impression, subjective version; objCGI, Clinical Global Impression, objective version; ISMI, Internalized Stigma of Mental IIIness; NS, not statistically significant.

Also, the patients with comorbid depression or other anxiety disorder and those with a positive family history of mental illness $(\mathrm{n}=53$ ) did not significantly differ from patients without these comorbidities or without a family history of selfstigma (Table 5). However, the individuals with a comorbid personality disorder tend to have significantly higher levels of self-stigma and its components when compared with those without this comorbidity (Table 5). Further, the mean levels of self-stigma and its components correlated with all of these measurements of the severity of mental disorder. It was positively connected to more intense symptoms of anxiety, depression, and overall severity of mental disorder as evaluated by both physician and patient (objCGI and subjCGI, Table 5).

\section{Self-stigma and personality factors}

The relationship between self-stigma and personality was explored using the focal points of Cloninger's theory of personality, Snyder's theory of hope, and dissociation. The results of the analysis are described in Table 6. Self-stigma, 
Table 6 Self-stigma and personality factors

\begin{tabular}{ll}
\hline Personality factors & Overall ISMI score \\
\hline NS & $r=0.04 ; \mathrm{NS}$ \\
HA & $r=0.66 ; P<0.00 I^{\mathrm{P}}$ \\
RD & $r=-0.2 I^{P} P<0.00 I^{\mathrm{P}}$ \\
PS & $r=-0.36 ; P<0.00 I^{\mathrm{P}}$ \\
SD & $r=-0.60 ; P<0.00 \mathrm{I}^{\mathrm{P}}$ \\
CO & $r=-0.27 ; P<0.0 \mathrm{I}^{\mathrm{P}}$ \\
ST & $r=0.10 ; \mathrm{NS}$ \\
Hope & $r=-0.60 ; P<0.00 \mathrm{I}^{\mathrm{P}}$ \\
DES score & $r=0.44 ; P<0.00 \mathrm{I}^{\mathrm{P}}$ \\
\hline
\end{tabular}

Notes: $P$, Pearson $r$, hope, overall score on the ADHS.

Abbreviations: ADHS, Adult Dispositional Hope Scale; NS, novelty seeking; HA, harm avoidance; RD, reward dependence; PS, persistence; SD, self-directedness; CO, cooperativeness; ST, self-transcendence; DES, Dissociative Experiences Scale; ISMI, Internalized Stigma of Mental Illness.

measured by the ISMI scale, correlated significantly and positively with harm avoidance and dissociation, including the pathological dissociation score. Conversely, it correlated significantly and negatively with reward dependence, persistence, self-directedness, cooperativeness, and hope, including both of its subscales (Table 6).

\section{Multiple regression analysis of significant factors connected to self-stigma}

Due to the numerous factors significantly related to selfstigma, we decided to perform a multiple regression analysis to identify the most important elements. The dependent variable was the overall level of the ISMI scale. The independent variables were comorbidity with a personality disorder, intensity of symptoms of anxiety (BAI) and depression (BDI-II), overall severity of mental disorder (objCGI), harm avoidance, reward dependence, persistence, self-directedness, cooperativeness, hope (ADHS), and dissociation (DES). The method applied was a backward stepwise regression. The resulting model explained $54.8 \%$ of the dependent variable $(P<0.001$, Table 7$)$. The most significant factors connected to self-stigma were harm avoidance, self-directedness, and intensity of symptoms of depression measured by BDI-II.

Table 7 Multiple regression analysis with self-stigma as the dependent variable

\begin{tabular}{lllll}
\hline Regressors & B & SE & Beta & Significance \\
\hline Hope & -0.197 & 0.117 & -0.203 & 0.097 \\
HA & 0.219 & 0.061 & 0.363 & 0.001 \\
PS & 0.088 & 0.049 & 0.171 & 0.078 \\
SD & -0.151 & 0.055 & -0.261 & 0.007 \\
BDI-II score & 0.218 & 0.100 & 0.198 & 0.032 \\
\hline
\end{tabular}

Abbreviations: HA, harm avoidance; PS, persistence; SD, self-directedness; BDI-II, Beck Depression Inventory-Second Edition; SE, standard error.

\section{Path analyses of self-stigma predictors}

Lastly, we tried to propose two causality models of factors predicting the probability of development of self-stigma. Both harm avoidance and self-directedness are traits that are formed in childhood and develop long before the occurrence of selfstigma (although self-directedness is also prone to changes later in life). Thus, we expected these two traits to be a factor of vulnerability (in the case of harm avoidance) and resilience (in the case of self-directedness) to self-stigma. This is in accordance with the results of the study by Margetić et al. ${ }^{22}$ We also thought of possible mediators of the relationship between these traits and self-stigma. When trying to identify the mediators of these connections, we searched for factors that would fulfill the requirements for mediators stated by Judd and Kenny. ${ }^{57}$ Specifically, we focused on hope as a possible mediator of a relationship between self-directedness and selfstigma. We also proposed a hypothesis according to which individuals who extensively dissociate in reaction to stress are more prone to development of self-stigma, and harm avoidance (ie, sensitivity to rejection and other forms of aversive stimuli) is a mediator of this relationship. When trying to identify the mediators of these connections, we searched for factors that would fulfill the requirements for the mediators stated by Judd and Kenny. ${ }^{60}$ The causal relationship with dissociation as a predictor may be valid because the tendency to dissociate usually develops in childhood as a reaction to excessive stress and trauma.$^{57,58}$ To identify dissociation as a factor significantly connected to harm avoidance, we performed another multiple regression with harm avoidance as a dependent factor and several regressors which significantly correlated with this trait (hope, anxiety, depression, dissociation, and severity of mental disorders evaluated by objCGI). The results of this regression analysis are described in Table 8.

The resulting model explained $59.1 \%$ of the dependent variables. The most significant predictors of harm avoidance were hope and dissociation. Another multiple regression was focused on the factors most significantly connected to self-directedness as the dependent variable (ie, hope, anxiety, depression, dissociation, age, and age of onset of mental disorder). The results are described in Table 9. The resultant model explained $58.6 \%$ of the dependent variable. The most

Table 8 Multiple regression analysis with harm avoidance as the dependent variable

\begin{tabular}{lllll}
\hline Regressors & B & SE & Beta & Significance \\
\hline Hope & -0.988 & 0.112 & -0.613 & 0.0001 \\
DES score & 0.515 & 0.106 & 0.335 & 0.0001 \\
\hline
\end{tabular}

Abbreviations: DES, Dissociative Experiences Scale; SE, standard error. 
Table 9 Multiple regression analysis with self-directedness as the dependent variable

\begin{tabular}{lllll}
\hline Regressors & B & SE & Beta & Significance \\
\hline Age & 0.609 & 0.110 & 0.379 & 0.0001 \\
Hope & 0.767 & 0.138 & 0.458 & 0.0001 \\
BDI-II score & -0.492 & 0.158 & -0.259 & 0.002 \\
\hline
\end{tabular}

Abbreviations: BDI-II, Beck Depression Inventory-Second Edition; SE, standard error.

significant predictors of self-directedness were the age of the participant with an anxiety disorder, hope, and the intensity of the symptoms of depression measured by BDI-II.

The multiple regressions showed that dissociation is significantly related to harm avoidance, and hope is connected to self-directedness. While other factors were also significantly connected to these two personality traits, their causal relationships are more unclear than the two proposed causal models. This is why we performed only these two path analyses and left other suggestions about causal relationships in the development of self-stigma to future research. Figure 1 describes the causal link between dissociation and self-stigma with harm avoidance as a mediator.

The first model supports the hypothesis that individuals who excessively dissociate under stress tend to be vulnerable toward the development of self-stigma. This relationship is entirely mediated by the harm avoidance trait. At this point of research, we cannot offer an explanation why these patients with anxiety disorders are prone to self-stigma. We can only offer hypotheses to be verified in future studies. However, we found that this relationship depends on the sensitivity of the patient to an aversive stimulus. This means that the more individuals excessively dissociate and suffer from anxiety disorders, sensitive to rejection, and nonacceptance, the more likely they are to stigmatize themselves. The second proposed model is described in Figure 2.

The second causal model also fits with the proposed hypothesis. A higher level of self-directedness seems to protect patients with anxiety disorders from the development of self-stigma. The relationship is partially mediated by the hope that explains approximately $39.0 \%$ of this

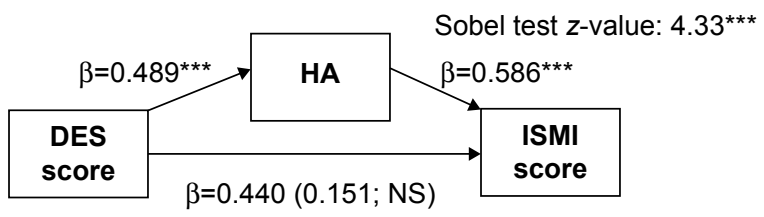

Figure I Causal relationship between dissociation, harm avoidance, and self-stigma. Note: $* * * P<0.001$

Abbreviations: DES, Dissociative Experiences Scale; HA, harm avoidance; ISMI, Internalized Stigma of Mental IIIness Scale; NS, non-significant.

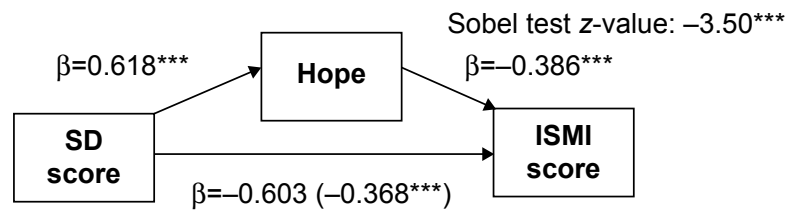

Figure 2 Causal relationship between self-directedness, hope, and self-stigma. Note: $* * * P<0.001$.

Abbreviations: SD, self-directedness; ISMI, Internalized Stigma of Mental Illness Scale.

effect. This suggests that individuals with higher levels of self-directedness are more able to be hopeful in hard times and able to sort out life problems, which protects them from the development of self-stigma. Both models are attempts to explain the relationships among the most significant factors connected to self-stigma. Further research should confirm or modify these findings.

\section{Discussion}

The goals of this research were to explore factors that may be significantly related to self-stigma in patients with anxiety disorders, and to suggest possible models of causality for the relationship between personality traits and self-stigma. The current research on this topic has focused mainly on patients with severe mental disorders, such as those with schizophrenia or affective disorders. ${ }^{5,939}$ Thus, it is not possible to compare our results with any other studies of self-stigma in patients with minor anxiety disorders. However, it is possible to compare our results with the findings of studies focusing on different patient groups. This process could eventually lead to a hypothesis about the similarity of the characteristics of self-stigma across diagnostic categories of mental illness.

Most of the research on the topic of self-stigma shows a positive connection between internalized stigma and higher intensity of symptoms of depression and greater overall severity of psychopathology. ${ }^{21}$ The results of the study presented here confirmed these findings in a group of patients with anxiety disorders. It is interesting that self-stigma was positively related to the severity of depressive symptoms but was not connected to the diagnosis of comorbid depression. The reason for this incongruence may lie in the fact that the patients with or without comorbid depression showed similar mean levels of depressive symptoms according to the BDI-II. This finding is in accordance with that of Livingston and Boyd, ${ }^{5}$ who concluded that specific psychiatric diagnoses do not influence the level of stigma.

Furthermore, it was confirmed that self-stigma (in patients with anxiety disorders) negatively correlates with hope. This is in accordance with the results of other studies. ${ }^{9,20}$ The same goes for the relationship between 
self-stigma and the overall level of anxiety. ${ }^{22,24}$ However, it was not possible to identify sources of the elevated anxiety or to confirm or disprove the thoughts of Corrigan et $\mathrm{al}^{22}$ or Vauth et $\mathrm{al}^{24}$ according to whom individuals with higher levels of self-stigma suffer mainly from anticipatory anxiety because they fear rejection. It is also possible that the elevated levels of anxiety in some of the participants in our study were primarily connected to the greater severity of the anxiety disorder and not directly to self-stigma. It is well known that, intensive and obtrusive feelings of anxiety are one of the core symptoms of anxiety disorder. ${ }^{36}$ Future studies should shed light on the relationship among anxiety, anxiety disorder, and self-stigma.

Summing up, these findings suggest that self-stigma may be related to similar psychosocial and clinical factors across the diagnostic spectrum of mental disorders. ${ }^{5,8,17,21}$ This hypothesis should be evaluated in future studies and meta-analyses.

Nevertheless, we identified comorbid personality disorders as a factor significantly elevating the tendency to develop self-stigma. This is in contrast with the findings of Livingston and Boyd $\mathrm{d}^{5}$ who stated that the particular type of mental disorder does not influence self-stigma. The difference between their results and ours may lie in the different patient groups included in the studies. While Livingston and Boyd ${ }^{5}$ studied mainly patients with schizophrenia and mood disorders, we focused on patients with anxiety disorders and possible comorbidities. Also, Rüsch et $\mathrm{al}^{61}$ found that women with borderline personality disorder tend to stigmatize themselves significantly more than women with social phobia. Future research could identify specific traits of vulnerability in patients with personality disorder that increase the probability of development of self-stigma. It is possible that early maladaptive schemas (about own unlovability or defectiveness) may predispose these patients to higher sensitivity toward interpersonal rejection and any signs of perceived "badness". ${ }^{64,65}$ Another explanation may relate to the finding that individuals with borderline personality disorder often experience more severe symptoms of anxiety and depression than patients without borderline personality disorder. Thus, elevated levels of self-stigma in patients with a comorbid personality disorder could be related to the severity of mental issues more than to the diagnosis of a personality disorder per se. ${ }^{66}$

To date, only two scientific works have focused on the relationship between self-stigma and personality traits, which have their basis in a complex theory of personality, eg, Cloninger's biosocial theory. ${ }^{25,67}$ Participants in both studies were individuals with schizophrenia. The first study identified two personality traits significantly related to selfstigma, ie, harm avoidance and self-directedness. The second study found that harm avoidance moderates the relationship between self-stigma and depression. ${ }^{67}$ Our study also found that harm avoidance and self-directedness are among the most significant factors connected with self-stigma in patients with anxiety disorder.

Margetić et $\mathrm{a}^{25}$ interpreted harm avoidance as a vulnerability factor and self-directedness as a resilience factor with regard to development of self-stigma. This is in accordance with the work of Cloninger, ${ }^{26}$ who thought of harm avoidance as a temperamental trait that is largely heritable and does not undergo significant changes in later life. Harm avoidance is a trait connected with sensitivity to aversive stimuli and a subsequent tendency to avoidant behavior. ${ }^{26}$ Thus, it seems meaningful that this personality trait should be a predictor of the occurrence of self-stigma. However, we also cannot reject the possibility that self-stigma may lead to a certain increase in harm avoidance. Namely, the increase in avoidant behavior and sensitivity to rejection could be expected. ${ }^{22,24}$

We also considered a potential effect of dissociation, because this has not been studied in relation to self-stigma. The results showed that dissociation was significantly related to both harm avoidance and self-stigma (even though it did not pass to the last step of the multiple regression with selfstigma as the dependent variable). Although dissociation may be a normal reaction to stress, and it is a natural part of our daily lives, ${ }^{68}$ excessive use of dissociation as a defense mechanism is problematic. ${ }^{6-71}$ The preference for dissociation as a coping strategy often forms in childhood as a result of excessive and usually chronic stress or trauma that is not possible for the child to solve or avoid otherwise. ${ }^{61-63}$ This is why we also considered the increasing tendency to dissociation as a factor of vulnerability toward self-stigma developed later in adulthood. This hypothesis was confirmed by a path analysis in which dissociation was a positive predictor of self-stigma. Further, we confirmed that this relationship is entirely mediated by the harm avoidance trait. This means that sensitivity toward rejection and other forms of stigmatizing behavior from the social environment leads patients with anxiety disorder and increased tendencies to dissociate to internalized stigma. Both harm avoidance and an excessive tendency to dissociate seem to be vulnerability factors in terms of the occurrence of self-stigma in adult patients with anxiety disorder. Nevertheless, it should be mentioned that the opposite causality in the relationship between self-stigma and dissociation is also possible. Thus, it will be important 
to explore further the connection between dissociation and self-stigma in the future.

The second path analysis dealt with the relationship between self-directedness and self-stigma. Cloninger ${ }^{42}$ stated that self-directedness changes across the life span. It is possible that self-stigma may also lead to decreased self-directedness. However, Snyder ${ }^{40}$ thought otherwise. While Snyder created a theory of hope, his developmental theories can also be applied in the case of self-directedness. Snyder ${ }^{40}$ thought that the ability to solve life issues in an adaptive way and be proactive rather than avoidant develops in the first years of life. Further development of this ability only fluctuates around the basis formed during childhood. While major changes are possible, they are unlikely without the shattering effects of trauma later in life or strengthening effects due to significant positive events or underwent psychotherapy ${ }^{40}$ The same may be true for self-directedness, a trait with some characteristics similar to those of the so-called hopeful personality. ${ }^{27,40}$ This theoretical knowledge partially validates the notion of Margetić et a ${ }^{25}$ about self-directedness being a factor of resiliency with regard to self-stigma. The second path analysis confirmed the hypothesis of the present authors. Self-directedness seems to be a protective factor that decreases the likelihood of development of self-stigma, and hope is partially a mediator of the relationship. This means that the ability to adaptively resolve one's own life issues and to be independent of others opinions and attitudes decreases the likelihood of the occurrence of self-stigma. ${ }^{72}$ Again, we cannot conclude that this model fully explains the relationship among self-stigma, hope, and self-directedness. The possibility that self-stigma leads to decreased hope and self-directedness should be evaluated and self-directedness should also be verified.

It should be stated, however, that both path analyses have methodological issues because they were performed as a part of a correlational study. Thus, our findings should be taken as suggestions or hypotheses rather than convincing proof of causality. Our research also has several other limitations. The participants were diagnosed with different types of anxiety disorder and with possible comorbid depression or personality disorder. It was a relatively variable sample, and the number of participants was relatively small. Further, the patients were hospitalized, and their symptomatology was more severe or otherwise unfavorable when compared with the majority of patients with anxiety disorder, who are usually treated in ambulatory care. Thus, the representativeness of the sample is limited. Most of the data was obtained using self-report measures, and only two methods (MINI and objCGI) were objective. Considering the proposed causal models, these should be taken as hypotheses and ideally confirmed by longitudinal studies. Many calculations were also performed, and the results of the numerous comparisons were not adjusted by other statistical methods.

The results of this study can help with our understanding of how self-stigma develops and what factors are related to it. Ideally, a better understanding of the process may be put to appropriate use in the treatment of anxiety disorder. Knowing the factors influencing the probability of occurrence of self-stigma, therapists could pay attention to them to decrease the likelihood of its development. While harm avoidance and other temperamental traits remain relatively stable across the life span and are therefore reasonably resistant to change, other factors such as self-directedness and hope are not. ${ }^{73}$ The risk of development of self-stigma could be decreased by focusing on the predictors. Because self-stigma seems to be one of the important predictors of treatment efficacy in neurotic disorders, this approach could bring significant benefits to the treatment of patients with anxiety disorder. ${ }^{74}$

Further research should also explore further the relationship between dissociation and self-stigma. It is also important to identify vulnerability and resilience factors associated with self-stigma and to incorporate the findings into the treatment of individuals with anxiety disorder.

\section{Conclusion}

Stigma is a concern for patients with various types of mental disorders. While most of the available studies have focused on the impact of stigma on individuals with severe mental disorders, eg, psychoses and mood disorders, many patients with anxiety disorders are faced with this problem as well, ${ }^{6,7}$ and a proportion of them also develop self-stigma. The results of this study suggest that internalized stigma in patients with anxiety disorder is mainly related to lower levels of self-directedness, higher levels of harm avoidance, and symptoms of depression. Two proposed models of causality were evaluated. It seems that individuals with anxiety disorder who excessively dissociate in times of stress are prone to the development of self-stigma, and this relationship is entirely mediated by harm avoidance. Conversely, patients with anxiety disorder who have higher levels of self-directedness are more resistant to self-stigma, and this resilience is partly mediated by the effect of hope. Future research should further focus on the factors influencing selfstigma and incorporation of the findings into the treatment of the anxiety disorders. 


\section{Disclosure}

The authors report no conflicts of interest in this work.

\section{References}

1. Phelan JC, Link BG, Stueve A, Pescosolido BA. Public conceptions of mental illness in 1950 and 1996: what is mental illness and is it to be feared? J Health Soc Behav. 2000;41:188-207.

2. Barlow K, Grenyer B, Ilkiw-Lavalle O. Prevalence and precipitants of aggression in psychiatric inpatient units. Aust N ZJ Psychiatry. 2000; 34:967-974.

3. Link BG, Phelan JC, Bresnahan M, Stueve A, Pescosolido BA. Public conceptions of mental illness: labels, causes, dangerousness, and social distance. Am J Public Health. 1999;89:1328-1333.

4. Padurariu M, Ciobica A, Persson C, Stefanescu C. Self-stigma in psychiatry: Ethical and bio-psycho-social perspectives. Romanian Journal of Bioethics. 2011;9:76-82.

5. Livingston JD, Boyd JE. Correlates and consequences of internalized stigma for people living with mental illness: a systematic review and meta-analysis. Soc Sci Med. 2010;71:2150-2161.

6. Alonso J, Buron A, Bruffaerts R, et al. World Mental Health Consortium. Association of perceived stigma and mood and anxiety disorders: results from the World Mental Health Surveys. Acta Psychiatr Scand. 2008;118:305-314.

7. Alonso J, Buron A, Rojas-Farreras S, et al. Perceived stigma among individuals with common mental disorders. J Affect Disord. 2009;118: 180-186.

8. Ritsher JB, Phelan JC. Internalized stigma predicts erosion of morale among psychiatric outpatients. Psychiatry Res. 2004;129:257-265.

9. Corrigan PW, Rafacz J, Rüsch N. Examining a progressive model of self-stigma and its impact on people with serious mental illness. Psychiatry Res. 2011;189:339-343.

10. Yanos PT, Roe D, Markus K, Lysaker PH. Pathways between internalized stigma and outcomes related to recovery in schizophrenia spectrum disorders. Psychiatr Serv. 2008;59:1437-1442.

11. Corrigan PW, Watson AC, Barr L. Understanding the self-stigma of mental illness. $J$ Soc Clin Psychol. 2006;25:875-884.

12. Mosanya TJ, Adelufosi AO, Adebowale OT, Oqunwale A, Adebayo OK. Self-stigma, quality of life and schizophrenia: an outpatient clinic survey in Nigeria. Int J Soc Psychiatry. 2014;60:377-386.

13. Cinculova A, Kamaradova D, Ociskova M, et al. [Self-stigma, treatment adherence, and medication discontinuation in anxiety disorders - a cross sectional study]. Ceska a Slovenska Psychiatrie. 2015;111:577-583. Czech.

14. Vrbova K, Kamaradova D, Latalova K, et al. Self-stigma and adherence to medication in patients with psychotic disorders - cross sectional study. Neuro Endocrinol Lett. 2014;35:645-652.

15. Hajda M, Kamaradova D, Latalova K, et al. [Self-stigma, treatment adherence, and medication discontinuation in patients with bipolar disorder in remission - a cross sectional study]. Psychiatrie Pro Praxi. In press. Czech.

16. Camp DL, Finlay WM, Lyons E. Is low self-esteem inevitable consequence of stigma? An example from women with chronic mental health problems. Soc Sci Med. 2002;55:823-834.

17. Latalova K, Prasko J, Kamaradova D, et al. Self-stigma and suicidality in patients with neurotic spectrum disorder - a cross sectional study. Neuro Endocrinol Lett. 2014;35:474-480.

18. Ociskova M, Prasko J, Dostalova L, et al. Self-stigma in psychiatric patients - standardization of the ISMI scale. Neuro Endocrinol Lett. 2014; 35:624-632.

19. Kamaradova D, Latalova K, Prasko J, et al. [Self-stigma, treatment adherence and medication discontinuation in mental disorders - a cross sectional study]. Psychiatrie. In press. Czech.

20. Mashiach-Eizenberg M, Hasson-Ohayon I, Yanos PT, Lysaker PH, Roe D. Internalized stigma and quality of life among persons with severe mental illness: the mediating roles of self-esteem and hope. Psychiatry Res. 2013;208:15-20.
21. Boyd JE, Adler EP, Otilingam PG, Peters T. Internalized Stigma of Mental Illness (ISMI) scale: a multinational review. Compr Psychiatry. 2014:55:221-231.

22. Corrigan PW, Larson JE, Rüsch N. Self-stigma and the "why try" effect: impact on life goals and evidence-based practices. World Psychiatry. 2009;8:75-81.

23. Rüsch N, Corrigan PW, Powell K, et al. A stress-coping model of mental illness stigma: II. Emotional stress responses, coping behavior and outcome. Schizophr Res. 2009;110:65-71.

24. Vauth R, Kleim B, Wirtz M, Corrigan PW. Self-efficacy and empowerment as outcomes of self-stigmatizing and coping in schizophrenia. Psychiatry Res. 2007;150:71-80.

25. Margetić BA, Jakovljević M, Ivanec D, Margetić B, Tošić G. Relations of internalized stigma with temperament and character in patients with schizophrenia. Compr Psychiatry. 2010;51:603-606.

26. Cloninger CR. A unified biosocial theory of personality and its role in the development of anxiety states. Psychiatr Dev. 1986;3:167-226.

27. Kose S. A psychobiological model of temperament and character: TCI. Yeni Symposium. 2003;41:86-97.

28. Ociskova M, Prasko J, Latalova K, et al. [Internalized stigma and the efficacy of pharmacotherapy and psychotherapy of anxiety disorders and neurotic disorders]. Ceska a Slovenska Psychiatrie. 2014;110:133-143. Czech.

29. Ross CA. Borderline personality disorder and dissociation. J Trauma Dissociation. 2007;8:71-80.

30. Bremner JD, Brett E. Trauma-related dissociative states and long-term psychopathology in posttraumatic stress disorder. Journal Trauma Stress. 1997;10:37-49.

31. Dell PF, O'Neil JA. Dissociation and the Dissociative Disorders: $D S M-V$ and Beyond. New York, NY, USA: Routledge; 2009.

32. Zlotnick C, Shea MT, Pearlstein T, Simpson E, Costello E, Begin A. The relationship between dissociative symptoms, alexithymia, impulsivity, sexual abuse, and self-mutilation. Compr Psychiatry. 1996;37:12-16.

33. Irwin HJ. Affective predictors of dissociation. II: Shame and guilt. J Clin Psychol. 1998;54:237-245.

34. Rugens A, Terhune DB. Guilt by dissociation: guilt primes augment the relationship between dissociative tendencies and state dissociation. Psychiatry Res. 2013;206:114-116.

35. Link BG, Phelan JC. Conceptualizing stigma. Annu Rev Sociol. 2001; 27:363-385.

36. World Health Organization. The ICD-10 Classification of Mental and Behavioural Disorders: Clinical Descriptions and Diagnostic Guidelines. Geneva, Switzerland: World Health Organization; 1992.

37. Sheehan DV, Lecrubier Y, Sheehan KH, et al. The Mini-International Neuropsychiatric Interview (M.I.N.I.): the development and validation of a structured diagnostic psychiatric interview for DSM-IV and ICD-10. J Clin Psychiatry. 1998;59 Suppl 20:22-33.

38. Amorim P. [Mini International Neuropsychiatric Interview (MINI): brief validation interview for diagnosing mental disorders]. Revista Brasileira de Psiquiatria. 2000;22:106-115. Portuguese.

39. Ritsher JB, Otilingam PG, Grajales M. Internalized stigma of mental illness: psychometric properties of a new measure. Psychiatry Res. 2003; 121:31-49.

40. Snyder CRR. Handbook of Hope: Theory, Measures, and Applications. New York, NY: Academic Press; 2000.

41. Ociskova M, Sobotkova I, Prasko J, et al. Standardization of the Adult Dispositional Hope Scale-The Czech version. Unpublished data.

42. Cloninger CR. The Temperament and Character Inventory (TCI) $-A$ Guide to its Development and Use. St Louis, MO: Centre for Psychobiology of Personality; 1994.

43. Farmer RF, Goldberg LR. A psychometric evaluation of the revised Temperament and Character Inventory (TCI-R) and the TCI-140. Psychol Assess. 2008;20:281-291.

44. Brändström S, Richter J, Nylander PO. Further development of the Temperament and Character Inventory. Psychol Rep. 2003;93:995-1002.

45. Preiss M, Kucharova J, Novak T, Stepankova H. The Temperament and Character Inventory-Revised (TCI-R): a psychometric characteristics of the Czech version. Psychiatr Danub. 2007;19:27-34. 
46. Guy W. ECDEU Assessment Manual for Psychopharmacology. Rockville, MD: US Department of Health, Education, and Welfare; 1976.

47. Zaider TI, Heimberg RG, Fresco DM, Schneier FR, Liebowitz MR. Evaluation of the Clinical Global Impression scale among individuals with social anxiety disorder. Psychol Med. 2003;33:611-622.

48. Beck AT, Epstein N, Brown G, Steer RA. An inventory for measuring clinical anxiety: psychometric properties. J Consult Clin Psychol. 1988;56: 893-897.

49. Beck AT, Steer RA. Relationship between the Beck Anxiety Inventory and the Hamilton Anxiety Rating Scale with anxious outpatients. J Anxiety Disord. 1991;5:213-223.

50. Steer RA. Amount of general factor saturation in the Beck Anxiety Inventory response of outpatients with anxiety disorders. J Psychopathol Behav Assess. 2009;31:112-118.

51. Kamaradova D, Prasko J, Latalova K, et al. [Validization of the Czech version of the Beck Anxiety Inventory]. Unpublished data. Czech.

52. Beck AT, Steer RA, Carbin MG. Psychometric properties of the Beck Depression Inventory: twenty-five years of evaluation. Clin Psychol Rev. 1988;8:77-100.

53. Storch EA, Roberti JW, Roth DA. Factor structure, concurrent validity, and internal consistency of the Beck Depression Inventory-Second Edition in a sample of college students. Depress Anxiety. 2004;19: 187-189.

54. Preiss M, Vacir K. [Beck Self-Report Depression Scale for Adults BDI-II]. Brno, Czech Republic: Psychodiagnostika; 1999.

55. Bernstein EM, Putnam FW. Development, reliability, and validity of a dissociation scale. J Nerv Ment Dis. 1986;174:727-735.

56. Waller NG, Ross CA. The prevalence and biometric structure of pathologic dissociation in the general population: taxometric and behavior genetic findings. J Abnorm Psychol. 1996;106:499-510.

57. Frischholz EJ, Braun BG, Sachs RG, et al. The Dissociative Experiences Scale: further replication and validation. Dissociation. 1990;3: $151-153$

58. Ptacek R, Bob P, Paclt I. [Dissociative Experiences Scale - Czech version]. Ceskoslovenska Psychologie. 2006;5:262-272. Czech.

59. European Medicines Agency. Guideline for Good Clinical Practice. London, UK: European Medicines Agency; 2002. Available from: http:// www.edctp.org/fileadmin/documents/EMEA_ICH-GCP_Guidelines_ July_2002.pdf. Accessed June 17, 2015.

60. Judd CM, Kenny DA. Process analysis: estimating mediation in treatment evaluations. Eval Rev. 1981;5:602-619.

61. Watson S, Chilton R, Fairchild H, Whewell P. Association between childhood trauma and dissociation among patients with borderline personality disorder. Aust N Z J Psychiatry. 2006;40:478-481.
62. Lyons-Ruth K, Dutra L, Schuder MR, Bianchi I. From infant attachment disorganization to adult dissociation: relational adaptations or traumatic experiences? Psychiatr Clin North Am. 2006;29:63-86.

63. Rüsch N, Hölzer A, Hermann C, et al. Self-stigma in women with borderline personality disorder and women with social phobia. J Nerv Ment Dis. 2006;194:766-773.

64. Fonagy P. Thinking about thinking: some clinical and theoretical considerations in the treatment of a borderline patient. Int J Psychoanal. 1991;72 Pt 4:639-656.

65. Linehan M. Cognitive-Behavioral Treatment of Borderline Personality Disorder. New York, NY: Guilford Press; 1993.

66. Comtois KA, Cowley DS, Dunner DL, Roy-Byrne PP. Relationship between borderline personality disorder and Axis I diagnosis in severity of depression and anxiety. J Clin Psychiatry. 1999;60:752-758.

67. Aukst-Margetić B, Jakšić N, Boričević Maršanić V, Jakovljević M. Harm avoidance moderates the relationship between internalized stigma and depressive symptoms in patients with schizophrenia. Psychiatry Res. 2014;219:92-94.

68. Putnam FW. Dissociation in Children and Adolescents: A Developmental Perspective. New York, NY: Guilford Press; 1997.

69. Lanius RA, Vermetten E, Loewenstein RJ, et al. Emotional modulation in PTSD: clinical and neurobiological evidence for a dissociative subtype. Am J Psychiatry. 2010;167:640-647.

70. Leavitt F. MMPI profile characteristics of women with varying levels of normal dissociation. J Clin Psychol. 2001;57:1469-1477.

71. Simeon D, Knutelska M, Smith L, Baker BR, Hollander E. A preliminary study of cortisol and norepinephrine reactivity to psychosocial stress in borderline personality disorder with high and low dissociation. Psychiatry Res. 2007;149:177-184.

72. Bosacki S, Innerd W, Towson S. Field independence-dependence and self-esteem in preadolescents: does gender make a difference? J Youth Adolesc. 1997;26:691-703.

73. Abrams KY, Yune SK, Kim SJ, et al. Trait and state aspects of harm avoidance and its implication for treatment in major depressive disorder, dysthymic disorder, and depressive personality disorder. Psychiatry Clin Neurosci. 2004;58:240-248.

74. Ociskova M, Prasko J, Kamaradova D, Grambal A, Latalova K, Sigmundova Z. Relationship between internalized stigma and treatment efficacy in mixed neurotic spectrum and depressive disorders. Neuro Endrocrinol Lett. 2014;35:711-717.
Neuropsychiatric Disease and Treatment

\section{Publish your work in this journal}

Neuropsychiatric Disease and Treatment is an international, peerreviewed journal of clinical therapeutics and pharmacology focusing on concise rapid reporting of clinical or pre-clinical studies on a range of neuropsychiatric and neurological disorders. This journa is indexed on PubMed Central, the 'PsycINFO' database and CAS,

\section{Dovepress}

and is the official journal of The International Neuropsychiatric Association (INA). The manuscript management system is completely online and includes a very quick and fair peer-review system, which is all easy to use. Visit http://www.dovepress.com/testimonials.php to read real quotes from published authors. 